\title{
Quantifying garnet-melt trace element partitioning using lattice-strain theory: new crystal-chemical and thermodynamic constraints
}

\author{
Wim van Westrenen · David S. Draper
}

Received: 16 August 2006/Accepted: 17 May 2007/Published online: 5 September 2007

(C) Springer-Verlag 2007

\begin{abstract}
Many geochemical models of major igneous differentiation events on the Earth, the Moon, and Mars invoke the presence of garnet or its high-pressure majoritic equivalent as a residual phase, based on its ability to fractionate critical trace element pairs ( $\mathrm{Lu} / \mathrm{Hf}, \mathrm{U} / \mathrm{Th}$, heavy REE/light REE). As a result, quantitative descriptions of mid-ocean ridge and hot spot magmatism, and lunar, martian, and terrestrial magma oceans require knowledge of garnet-melt partition coefficients over a wide range of conditions. In this contribution, we present new crystalchemical and thermodynamic constraints on the partitioning of rare earth elements (REE), Y and Sc between garnet and anhydrous silicate melt as a function of pressure $(P)$, temperature $(T)$, and composition $(X)$. Our approach is based on the interpretation of experimentally determined values of partition coefficients $D$ using lattice-strain theory. In this and a companion paper (Draper and van Westrenen this issue) we derive new predictive equations for the ideal ionic radius of the dodecahedral garnet $\mathrm{X}$-site, $r_{0}(3+)$, its apparent Young's modulus $E_{\mathrm{X}}(3+)$, and the strain-free partition coefficient $D_{0}(3+)$ for a fictive REE element $\mathrm{J}$ of ionic radius $r_{0}(3+)$. The new calibrations remedy several shortcomings of earlier lattice-strain based attempts to
\end{abstract}

Communicated by T. L. Grove.

W. van Westrenen $(\bowtie)$

Faculty of Earth and Life Sciences,

Vrije Universiteit Amsterdam, De Boelelaan 1085,

1081 HV Amsterdam, The Netherlands

e-mail: wim.van.westrenen@falw.vu.nl

D. S. Draper

Institute of Meteoritics,

Department of Earth and Planetary Sciences,

University of New Mexico, Albuquerque,

NM 87131-1136, USA model garnet-melt partitioning. A hitherto irresolvable temperature effect on $r_{0}(3+)$ is identified, as is a pronounced decrease in $E_{\mathrm{X}}(3+)$ as $\mathrm{Al}$ on the garnet $\mathrm{Y}$ site is progressively replaced by quadruvalent cations $(\mathrm{Si}, \mathrm{Ti})$ as pressure and garnet majorite content increase. $D_{0}(3+)$ can be linked to the free energy of fusion of a hypothetical rareearth garnet component $\mathrm{JFe}_{2} \mathrm{Al}_{3} \mathrm{Si}_{2} \mathrm{O}_{12}$ through simple activity-composition relations. By combining the three lattice-strain parameter models, garnet-anhydrous melt and majorite-anhydrous melt $D$ values for the REE, Y and Sc can be predicted from $P, T$, garnet major element composition, and melt iron content at pressures from 2.5-25 GPa and temperatures up to $2,573 \mathrm{~K}$, covering virtually the entire $P-T$ range over which igneous garnets are stable in solar system compositions. Standard deviations of the difference between predicted and observed $D_{\mathrm{REE}, \mathrm{Y}, \mathrm{Sc}}$ range from $25 \%$ for $\mathrm{Er}$ to $70 \%$ for Ce, and are not correlated with trace element mass. The maximum error in $D$ prediction ( $n$ $>300$ ) is $218 \%$ for one measurement of $D_{\text {Dy }}$. This is remarkably low considering the total spread in $D$ values of over four orders of magnitude.

\section{Introduction}

Trace elements are sensitive trackers of magmatic processes, due to their passive nature and widely varying physical and chemical properties (e.g., Goldschmidt 1937; Shaw 1953; Blundy and Wood 2003a). Quantitative models to constrain partial melting and crystallisation in the interiors of the Earth and other rocky planetary bodies (e.g., Neumann et al. 1954; Gast 1968; Shaw 1970; Allègre and Minster 1978; Zou and Reid 2001) all require mineralmelt partition coefficients $D$ (where $D$ is the concentration 
ratio between mineral and melt, following the terminology of Beattie et al. 1993) as input parameters. Although they are often assumed to be constant, $D$ 's are thermodynamic variables, changing as a function of pressure, temperature, and composition (e.g., Hertogen and Gijbels 1976; Beattie 1994; Blundy and Wood 1994, 2003a, b; Wood and Blundy 2001, 2002; Gaetani 2004; Mysen 2004; Prowatke and Klemme 2005).

The crystal lattice-strain model (Blundy and Wood 1994, 2003a, b) provides a convenient framework for the development of models that quantify the extent of these $D$ variations. This model builds upon the observation, first made by Onuma et al. (1968), that the logarithms of mineral-melt partition coefficients $D_{i}$ for a series of trace elements $i$ with charge $j+$, substituting onto a particular crystal lattice site, show a near-parabolic dependence on trace element radius $r_{i}$ (Fig. 1a). This dependence can be related to the energetics of exchanging major and trace elements in both crystal and co-existing melt, if it is assumed that these energetics are dominated by the crystal lattice-strain energy (Nagasawa 1966; Brice 1975) required to accommodate a misfit trace element in a crystal lattice site.

The resulting lattice-strain model uses three parameters to describe $D$ variations (Eq. 1, Fig. 1a): (1) The 'ideal radius' $r_{0}$ for a (fictive) element with charge $j+$ that does not strain the crystal lattice and hence has the largest mineral-melt $D$. (2) The maximum partition coefficient $D_{0}$ for this 'ideally sized' element. (3) The apparent Young's modulus $E$ of the site, which is a measure of the resistance of the crystal lattice to the incorporation of elements with radii larger or smaller than the ideal radius $r_{0}$.

$D_{i}=D_{0} \exp \left(\frac{-4 \pi E N_{\mathrm{A}}\left(\frac{r_{0}}{2}\left(r_{i}-r_{0}\right)^{2}+\frac{1}{3}\left(r_{i}-r_{0}\right)^{3}\right)}{R T}\right)$

Fig. 1 a Sketch showing parameters of the lattice-strain model (Eq. 1) in relation to the observed near-parabolic dependence of $\log (D)$ on trace element radius. b Examples of measured garnet-melt partition coefficients (symbols, data from Corgne and Wood (2003) and Pertermann et al. (2004) for $\mathrm{REE}, \mathrm{Sc}$, and $\mathrm{Y}$ showing parabolic behaviour. Curves are fits of Eq. 1 to the data a

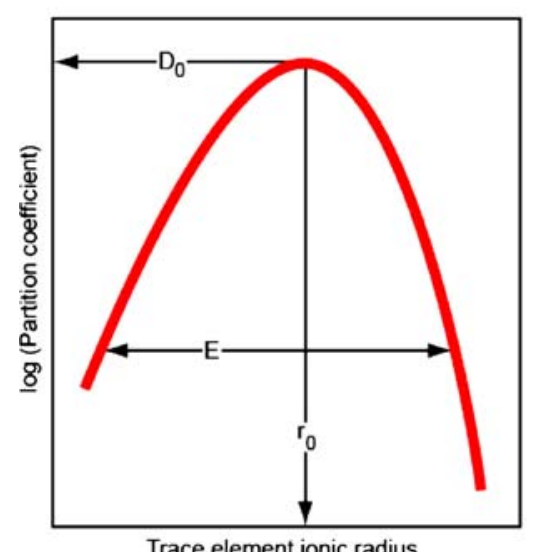

Trace element ionic radius where $R$ is gas constant, $T$ in Kelvin, and $N_{\mathrm{A}}$ Avogadro's number.

Here, we present a lattice-strain based thermodynamic model for the partitioning of REE, Y and Sc between garnet, majorite and anhydrous silicate melt applicable at pressures from 2.5 to $25 \mathrm{GPa}$. Many geochemical models of major igneous differentiation events on the Earth, Mars, and the Moon invoke the presence of garnet or majorite (a mineral with the garnet structure, but containing significantly higher $\mathrm{Si}$ and lower $\mathrm{Al}$ concentrations) as a residual phase (e.g., Kato et al. 1988; Drake et al. 1993; Neal 2001; Borg and Draper 2003; Corgne and Wood 2004; Walter et al. 2004), based on the ability of these minerals to fractionate critical trace element pairs (e.g., Lu/Hf, U/Th, heavy REE/light REE). Quantitative descriptions of midocean ridge and hot spot magmatism, and lunar, martian, and terrestrial magma ocean evolution thus require knowledge of garnet-melt partition coefficients over a wide range of conditions (e.g., Salters and Longhi 1999; van Westrenen et al. 1999, 2000a; Klemme et al. 2002; Salters et al. 2002; Bennett et al. 2004; Pertermann et al. 2004; Corgne and Wood 2004; Draper et al. 2003, 2006; Dwarzski et al. 2006).

A sketch of the cubic garnet crystal structure (e.g., Gibbs and Smith 1965; Ungaretti et al. 1995) is shown in Fig. 2. The structure consists of a 3D network of interconnected polyhedra including X-site dodecahedra, Y-site octahedra, and $\mathrm{Z}$-site tetrahedra, leading to the general formula $\mathrm{X}_{3} \mathrm{Y}_{2} \mathrm{Z}_{3} \mathrm{O}_{12}$. Majorite-free aluminosilicate garnets of interest to Earth Science have the general formula $\mathrm{X}_{3} \mathrm{Al}_{2} \mathrm{Si}_{3} \mathrm{O}_{12}$, where the major element composition of the $\mathrm{X}$-site is dominated by a mixture of divalent $\mathrm{Ca}, \mathrm{Mg}, \mathrm{Mn}$, and Fe. Both garnet-melt partitioning studies and EXAFS measurements show that the REE replace these divalent X-site cations (e.g., van Westrenen et al. 1999; Quartieri et al. 1999a, b, 2002, 2004). As pressure increases, excess b Applicability of lattice strain model to garnet-melt partitioning of REE, $Y$ and Sc

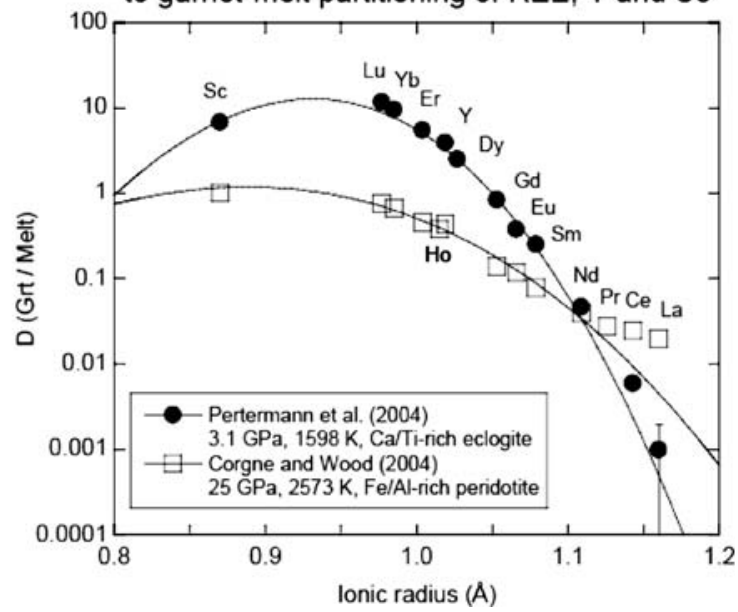




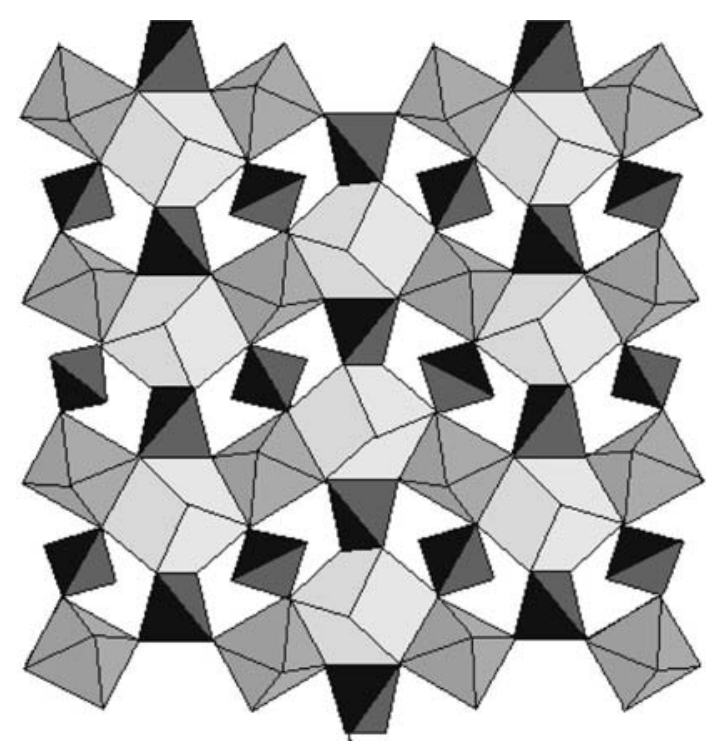

Fig. 2 Two-dimensional projection of the build-up of the garnet and majorite structures, after Merli et al. (1995). Alternating isolated tetrahedra (black, enclosing the $\mathrm{Z}$ site) and octahedra (dark grey, enclosing the $\mathrm{Y}$ site) form a 3D corner-sharing network, with the resulting cavities forming dodecahedra (light grey, enclosing the $\mathrm{X}$ site)

$\mathrm{Si}$ is incorporated into the garnet structure by replacing $\mathrm{Al}$ in the Y-site. Garnets with $>3 \mathrm{Si}$ and $<2 \mathrm{Al}$ atoms per formula unit (apfu) are classified as 'majoritic garnet' or 'majorite'.

The large extent of the $P-T$ stability field of garnet and majorite, combined with the substantial variations in published garnet-anhydrous melt $D$ values for the REE of up to four orders of magnitude, make this a highly suitable test case for the limits of application of lattice-strain models. Previous attempts at formulating predictive garnet-melt REE partitioning models (van Westrenen et al. 2001; Wood and Blundy 2002) failed to predict correctly both majorite-melt $D$ 's (Draper et al. 2003, 2006; Dwarzski et al. 2006) and garnet-melt $D$ 's at low temperatures (e.g., Klemme et al. 2002; Bennett et al. 2004; Pertermann et al. 2004). As shown in this and a companion paper (Draper and van Westrenen this issue), experimental data published over the past 6 years allow lattice-strain based constraints on $D$ variations to be improved significantly.

This manuscript presents the data base used for the development of the predictive models, and describes the new crystal-chemical and thermodynamic constraints on $r_{0}$, $E$ and $D_{0}$ variations derived from it. In the Draper and van Westrenen (this issue) companion paper a complementary approach is taken to predicting variations in the three lattice-strain model parameters. Detailed statistical evaluations of correlations between intensive and extensive controlling parameters are presented, allowing for the incorporation of terms that reflect a contribution from melt composition in predicting variations in $D_{0}$. The resulting $D_{0}$ model performs as well as the thermodynamic model presented in this paper. By combining the new lattice-strain parameter models, garnet-melt and majorite-melt $D$ values for the REE, Y and Sc can be predicted in anhydrous systems at pressures from 2.5 to $25 \mathrm{GPa}$ and temperatures up to $2,573 \mathrm{~K}$, covering virtually the entire $P-T$ range over which igneous garnets are stable in solar system compositions.

\section{Methods}

A total of 57 published experimental garnet-anhydrous melt and majorite-anhydrous melt partitioning data sets (Table 1) were considered for the construction of predictive models, representing a threefold increase compared to previous work (van Westrenen et al. 2001; Wood and Blundy 2002). The $P-T$ field covered by the data is shown in Fig. 3. Pressures in the experiments ranged from 2.4 to $25 \mathrm{GPa}$, and temperatures covered a range from 1,603 to $2,573 \mathrm{~K}$. The pioneering majorite-melt partitioning studies of Kato et al. (1988), Ohtani et al. (1989), Yurimoto and Ohtani (1992), and Moriyama et al. (1992) were not incorporated to exclude the possibility of partitioning data artefacts, related to the short run durations and small grain sizes employed in these studies (see discussion in Corgne and Wood 2004), although as detailed in Draper and van Westrenen (this issue), statistical analyses do not identify results of these studies as major outliers.

Three notable improvements in the input data set are: (1) Improved temperature coverage at a pressure of $3 \pm$ $0.2 \mathrm{GPa}$. (2) Improved coverage at pressures exceeding $5 \mathrm{GPa}$. (3) Improved compositional coverage, including martian and terrestrial mantle compositions that produce garnets with significant majorite components (Draper et al. 2003, 2006; Walter et al. 2004; Corgne and Wood 2004), eclogitic bulk compositions (Klemme et al. 2002; Bennett et al. 2004), Ti-rich terrestrial compositions (Pertermann et al. 2004), and very Ti-rich compositions relevant to melting in the lunar mantle (Dwarzski et al. 2006).

Measured $\mathrm{REE} / \mathrm{Y} / \mathrm{Sc} D$ values for these experiments were fitted to Eq. 1 for each experiment, using a Levenberg-Marquardt-type weighted non-linear least-squares fitting routine (Press et al. 1992). Two representative sample data sets and corresponding best-fit curves are shown in Fig. 1b. Systematic trends in $r_{0}, E$, and $D_{0}$ were linked quantitatively to variations in garnet/majorite crystal-chemical composition, melt composition, temperature, and pressure, to arrive at a predictive lattice-strain based partitioning model. 
Table 1 Pressure-temperature conditions for anhydrous garnet-melt and majorite-melt partitioning experiments considered in this study

\begin{tabular}{|c|c|c|c|c|c|c|c|}
\hline References & Experiment & $P(\mathrm{GPa})$ & $T(\mathrm{~K})$ & References & Experiment & $P(\mathrm{GPa})$ & $T(\mathrm{~K})$ \\
\hline Salters et al. (2002) & TM1295-10 & 2.4 & 1,738 & van Westrenen et al. (1999) & 14 & 3.0 & 1,803 \\
\hline Hauri et al. (1994) & & 2.5 & 1,703 & van Westrenen et al. (2000a) & 18 & 3.0 & 1,811 \\
\hline Salters et al. (2002) & BK797-3 & 2.8 & 1,853 & Withers (1997) & AOB 1.08 & 3.0 & 1,743 \\
\hline Salters et al. (2002) & RD-893-6 & 2.8 & 1,858 & Withers (1997) & AOB1.11 & 3.0 & 1,760 \\
\hline Salters et al. (2002) & MO1295-3 & 2.8 & 1,788 & Pertermann et al. (2004) & MP236 & 3.1 & 1,598 \\
\hline Salters and Longhi (1999) & TM694-3 & 2.8 & 1,808 & Salters et al. (2002) & RD1097-4 & 3.2 & 1,873 \\
\hline Salters and Longhi (1999) & TM694-6 & 2.8 & 1,820 & Salters et al. (2002) & RD1097-5 & 3.2 & 1,883 \\
\hline Salters and Longhi (1999) & TM295-4 & 2.8 & 1,813 & Salters et al. (2002) & RD1097-7 & 3.4 & 1,908 \\
\hline Salters and Longhi (1999) & MO895-1 & 2.8 & 1,823 & Salters et al. (2002) & RD1097-8 & 3.4 & 1,933 \\
\hline Salters and Longhi (1999) & MO895-2 & 2.8 & 1,803 & Draper et al. (2006) & A67 & 3.5 & 2,048 \\
\hline Salters and Longhi (1999) & MO895-3 & 2.8 & 1,773 & Draper et al. (2006) & A138 & 4.0 & 1,873 \\
\hline Salters and Longhi (1999) & TM1295-2 & 2.8 & 1,788 & Draper et al. (2006) & A140 & 4.5 & 1,873 \\
\hline Pertermann et al. (2004) & A343 & 2.9 & 1,663 & Rocholl et al. (1996) & 829 & 5.0 & 1,853 \\
\hline van Westrenen et al. (2000a) & 16 & 2.9 & 1,813 & Rocholl et al. (1996) & 832 & 5.0 & 1,913 \\
\hline Bennett et al. (2004) & SB/4/2000 & 3.0 & 1,675 & Draper et al. (2006) & A221 & 5.0 & 1,923 \\
\hline Bennett et al. (2004) & SB/8/2001 & 3.0 & 1,603 & Draper et al. (2006) & A228 & 5.0 & 1,898 \\
\hline Johnson (1998) & & 3.0 & 1,703 & Draper et al. (2003) & $\mathrm{R} 223+\mathrm{R} 243$ & 5.0 & 2,023 \\
\hline Klemme et al. (2002) & $\mathrm{BS} 21$ & 3.0 & 1,673 & Dwarzski et al. (2006) & A85 & 5.5 & 1,923 \\
\hline Pertermann et al. (2004) & MP169 & 3.0 & 1,628 & Dwarzski et al. (2006) & A161 & 5.5 & 1,943 \\
\hline Pertermann et al. (2004) & MP214 & 3.0 & 1,633 & Dwarzski et al. (2006) & A119 & 6.3 & 1,973 \\
\hline Pertermann et al. (2004) & MP240 & 3.0 & 1,613 & Dwarzski et al. (2006) & A103 & 7.0 & 1,923 \\
\hline Pertermann et al. (2004) & MP220 & 3.0 & 1,623 & Draper et al. (2003) & $\mathrm{R} 180+\mathrm{R} 252$ & 7.0 & 2,133 \\
\hline Pertermann et al. (2004) & MP216 & 3.0 & 1,623 & Draper et al. (2003) & $\mathrm{R} 242+\mathrm{R} 236$ & 7.0 & 2,048 \\
\hline Pertermann et al. (2004) & MP237 & 3.0 & 1,623 & Draper et al. (2006) & A229 & 7.0 & 2,048 \\
\hline Pertermann et al. (2004) & MP254 & 3.0 & 1,623 & Draper et al. (2003) & $\mathrm{R} 244+\mathrm{R} 233$ & 9.0 & 2,073 \\
\hline van Westrenen et al. (1999) & 8 & 3.0 & 1,833 & Walter et al. (2004) & 62 & 23 & 2,573 \\
\hline van Westrenen et al. (1999) & 11 & 3.0 & 1,838 & Walter et al. (2004) & 249 & 23.5 & 2,573 \\
\hline van Westrenen et al. (1999) & 12 & 3.0 & 1,818 & Corgne and Wood (2004) & & 25 & 2,573 \\
\hline van Westrenen et al. (1999) & 13 & 3.0 & 1,803 & & & & \\
\hline
\end{tabular}

\section{Results and discussion}

A new model for $r_{0}$

Fitted values of $r_{0}$ vary from 0.88 to $0.99 \AA$. Experiments at constant pressure $(3 \pm 0.1 \mathrm{GPa})$ and temperature $(1,818 \pm 15 \mathrm{~K})$ and varying bulk composition previously showed that $r_{0}$ for the REE, Y and Sc is linked linearly to garnet X-site composition (van Westrenen et al. 1999, 2000a):

$$
\begin{aligned}
& r_{0}(\AA \text { at } 3 \mathrm{GPa}, 1818 \mathrm{~K})=0.9302 X_{\mathrm{Py}}+0.993 X_{\mathrm{Gr}} \\
& \quad+0.916 X_{\mathrm{Alm}}+0.946 X_{\mathrm{Spes}}+1.05\left(X_{\mathrm{And}}+X_{\mathrm{Uv}}\right)
\end{aligned}
$$

where $X$ is mole fraction, Py = pyrope $\left(\mathrm{Mg}_{3} \mathrm{Al}_{2} \mathrm{Si}_{3} \mathrm{O}_{12}\right)$, $\mathrm{Gr}=$ grossular $\left(\mathrm{Ca}_{3} \mathrm{Al}_{2} \mathrm{Si}_{3} \mathrm{O}_{12}\right)$, Alm = almandine $\left(\mathrm{Fe}_{3} \mathrm{Al}_{2} \mathrm{Si}_{3} \mathrm{O}_{12}\right)$, Spes = spessartine $\left(\mathrm{Mn}_{3} \mathrm{Al}_{2} \mathrm{Si}_{3} \mathrm{O}_{12}\right)$,
And $=$ andradite $\quad\left(\mathrm{Ca}_{3} \mathrm{Fe}_{2} \mathrm{Si}_{3} \mathrm{O}_{12}\right), \quad$ and $\quad \mathrm{Uv}=$ uvarovite $\left(\mathrm{Ca}_{3} \mathrm{Cr}_{2} \mathrm{Si}_{3} \mathrm{O}_{12}\right)$.

Based on observed variations in $r_{0}$ in a limited number of experiments performed at pressures between 2.5 and $5 \mathrm{GPa}$, the pressure dependence of $r_{0}$ was previously constrained to $-0.005 \AA / \mathrm{GPa}$ (van Westrenen et al. 2000a). This pressure dependence leads to severe mismatches between observed and predicted $r_{0}$ at pressures near the upper pressure stability limit of majorite ( $>20 \mathrm{GPa}$ ). For example, the van Westrenen et al. (2000a, 2001) calibration predicts $r_{0}=0.82 \AA$ for the Corgne and Wood (2004) and Walter et al. (2004) experiments at 23-25 GPa, compared to the observed values that range from 0.88 to $0.91 \AA$.

In the new model, the measured pressure dependence of the dimensions of the large dodecahedral garnet X-site, on which the REE are known to reside (e.g., Quartieri et al. 1999a, b, 2002, 2004), is used as an independent means to 


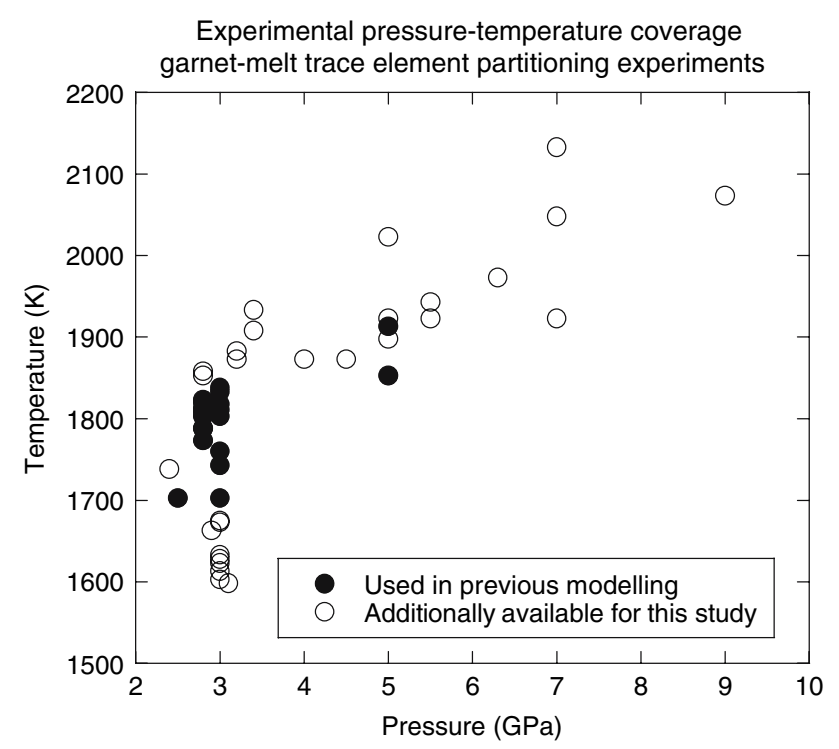

Fig. 3 Pressure-temperature conditions of experimental garnetanhydrous melt partitioning data sets used in this study, compared to the earlier work of van Westrenen et al. (2001) and Wood and Blundy (2002). Not shown are three data sets at 23-25 GPa and 2,573 K (Walter et al. 2004; Corgne and Wood 2004), included in this study and absent from the 2001 and 2002 data bases

constrain the pressure dependence of $r_{0}$. The decrease in average dodecahedral cation-oxygen distance $\langle\mathrm{X}-\mathrm{O}\rangle$ with increasing pressure was determined to high accuracy by Zhang et al. (1998) for end-member pyrope $\left(\mathrm{Mg}_{3} \mathrm{Al}_{2-}\right.$ $\mathrm{Si}_{3} \mathrm{O}_{12}$ ) garnet (Fig. 4). These data were taken to be representative for the behaviour of $r_{0}$ in all garnet and majorite

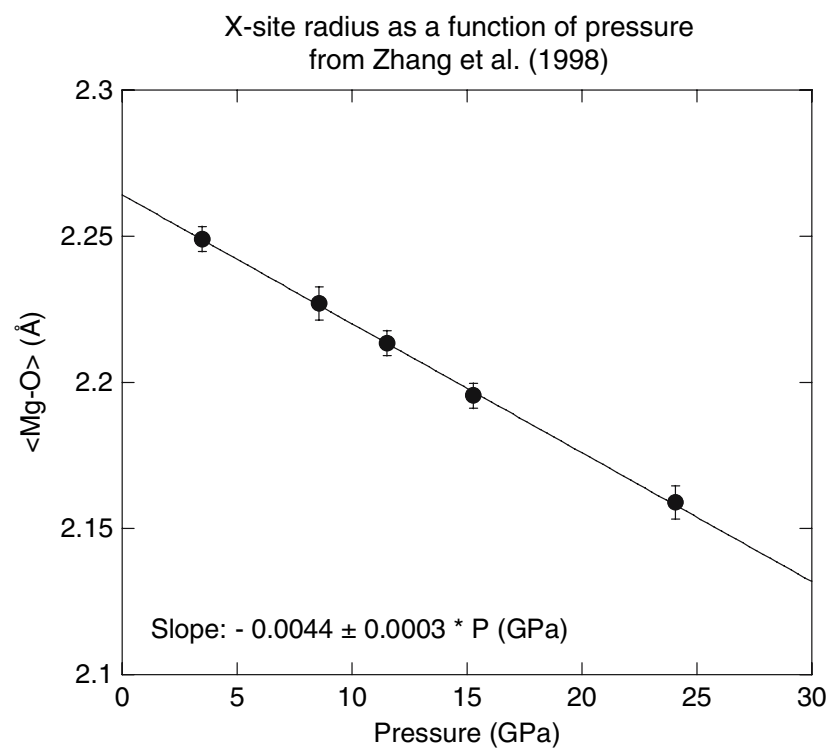

Fig. 4 Variation of average $\mathrm{Mg}-\mathrm{O}$ distance in $\mathrm{Mg}_{3} \mathrm{Al}_{2} \mathrm{Si}_{3} \mathrm{O}_{12}$ pyrope, $<\mathrm{Mg}-\mathrm{O}>$, as a function of pressure between 2.5 and $25 \mathrm{GPa}$, taken from single crystal X-ray diffraction refinements of Zhang et al. (1998) compositions. As shown in Fig. 4, $<\mathrm{X}-\mathrm{O}>$ varies linearly across the complete pressure range relevant to igneous garnet/majorite stability (i.e., between 2.5 and $25 \mathrm{GPa}$ ), leading to a predicted change in $r_{0}$ of $-0.0044 \pm 0.0003 \AA$ / GPa.

The preponderance of experiments at $3 \pm 0.1 \mathrm{GPa}$ (Table 1, Fig. 3) allows for the unambiguous identification of a clear temperature dependence of $r_{0}$, with $r_{0}$ varying at a rate of $0.000058 \pm 0.000007 \AA / K$ (Fig. 5). Although intuitively it seems reasonable to expect an increase in $r_{0}$ values with increasing temperature as crystal lattices expand, due to the small temperature ranges involved this effect could not be resolved previously in lattice-strain based REE mineral-melt partitioning models. The resulting predictive equation for $r_{0}$ incorporating both compositional, $P$, and $T$ effects (with compositions given in terms of mole fractions of the garnet end-members, $P$ in GPa, and $T$ in Kelvin, and taking the values of $3 \mathrm{GPa}$ and $1,818 \mathrm{~K}$ mentioned above as anchor points) is given below (Eq. 3):

$$
\begin{aligned}
r_{0}(\mathrm{REE}, \AA)= & 0.9302 X_{\mathrm{Py}}+0.993 X_{\mathrm{Gr}}+0.916 X_{\mathrm{Alm}} \\
& +0.946 X_{\mathrm{Spes}}+1.05\left(X_{\mathrm{And}}+X_{\mathrm{Uv}}\right) \\
& -0.0044( \pm 0.0003)(P-3) \\
& +0.000058( \pm 0.000007)(T-1818) .
\end{aligned}
$$

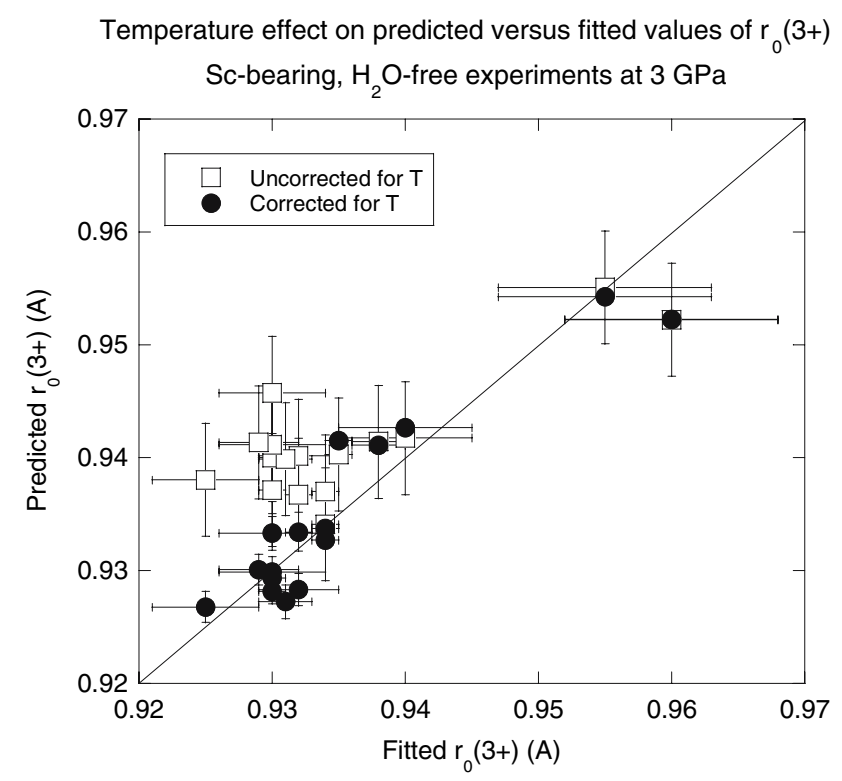

Fig. 5 Comparison between predicted and observed values of $r_{0}$ for REE partitioning between garnet and anhydrous silicate melt at $3 \mathrm{GPa}$ (taken from references listed in Table 1). Open symbols depict predictions using the $r_{0}$ model of van Westrenen et al. $(2000 \mathrm{a}, \mathrm{b})$ (Eq. 2), showing significant overestimation of $r_{0}$ at low values of fitted $r_{0}$ (coinciding with experiments performed at relatively low temperatures). Linear regression analysis leads to the identification of a significant temperature effect on $r_{0}$. Incorporation of this effect into the predictive model for $r_{0}$ (filled symbols, obtained using Eq. 3) leads to significant reduction of the mismatch between observed and predicted values 
For majoritic garnets, mole fractions to be used in Eq. 3 were calculated as follows: First, all $\mathrm{Ca}, \mathrm{Fe}^{2+}, \mathrm{Mn}^{2+}, \mathrm{Na}$ and $\mathrm{K}$ was assigned to the large $\mathrm{X}$ site. $\mathrm{Mg}$ was then divided between the $\mathrm{X}$-site (leading to a total of three cations per formula unit) and the $\mathrm{Y}$ site. The pyrope fraction $X_{\mathrm{Py}}$ was then calculated looking at the $X$-site composition only. We opted to assume only $\mathrm{Mg}$ entered the smaller majorite $\mathrm{Y}$-site, because it is the smallest of the major $1+/ 2+$ cations in majorite. Alternative site assignments (e.g., partially assigning $\mathrm{Fe}^{2+}, \mathrm{Mn}$ and $\mathrm{Mg}$ to the $\mathrm{Y}$-site) would lead to a slightly different fit parameter for the temperature dependence in Eq. 3.

Equation 3 predicts $r_{0}$ for all 57 experimental data sets to within $0.017 \AA(1 \sigma)$, compared to $0.032 \AA \quad(1 \sigma)$ achievable with van Westrenen et al. (2000a, 2001). The 2001 model performed increasingly badly as pressure increased towards the upper majorite stability limit of approximately $25 \mathrm{GPa}$ in terrestrial mantle compositions (Walter et al. 2004; Corgne and Wood 2004). Crucially, the new model shows no correlation between absolute and relative values of $r_{0}$ misfit and experimental pressure.

Notably, this major improvement was achieved without introducing into Eq. 3 any explicit term dealing with variations in garnet octahedral $\mathrm{Y}$ site composition, related to the incorporation of excess $\mathrm{Si}$ (in the case of majoritebearing garnets) or $\mathrm{Ti}$ (in the case of Ti-rich experiments). Ostensibly, within the accuracy required for interpreting element partitioning data, the effective radius $r_{0}$ of the large dodecahedral $\mathrm{X}$ site in garnet and majorite appears unaffected by changes in the compositions of the $\mathrm{Y}$ (and tetrahedral Z) sites. Neither increasing garnet Ti content (Bennett et al. 2004; Pertermann et al. 2004; Dwarzski et al. 2006), nor increasing majorite content with increasing pressure (Draper et al. 2003, 2006; Corgne and Wood 2004; Walter et al. 2004) affect $r_{0}$ for the REE. As discussed in the next section, this contrasts sharply with observed variations of the apparent Young's modulus $E$ of the garnet $\mathrm{X}$ site, predictions of which do require explicit incorporation of the effect of the presence of $\mathrm{Si}$ and/or $\mathrm{Ti}$ on the garnet $\mathrm{Y}$ site.

\section{A new model for $E$}

The observed apparent Young's modulus $E$ for trivalent trace elements entering the garnet $\mathrm{X}$ site is large, both in absolute terms, and in relative terms compared to $E$ values for trivalent cations entering crystallographic sites in other important igneous minerals, such as the clinopyroxene M2 site (e.g., Wood and Blundy 1997). Fitted 3+E values for the experiments listed in Table 1 range from $465 \pm 40 \mathrm{GPa}$ to $730 \pm 32 \mathrm{GPa}$. These high values reflect the ability of garnet to fractionate heavy from light REE to a much larger extent than most other major rock-forming minerals, leading to steep REE patterns in melts produced in the presence of residual garnet (the so-called 'garnet signature' identified in many terrestrial mantle melts, e.g., Salters and Hart 1989; Shen and Forsyth 1995; Hellebrand et al. 2002).

Blundy and Wood (1994) used an empirical relationship derived from a compilation of elastic property measurements of polyhedra in minerals (Hazen and Finger 1979) to link the Young's modulus of a polyhedron enclosing a crystal lattice site to the site effective radius $r_{0}$ and the charge $Z_{\mathrm{c}}$ of the cation occupying the site:

$E(\mathrm{GPa})=1125( \pm 30) Z_{\mathrm{c}}\left(1.38+r_{0}(\AA)\right)^{-3}$.

The good agreement between apparent Young's moduli derived by fitting Eq. 1 to REE plagioclase-melt and clinopyroxene M2 site-melt partitioning data, and actual measurements of plagioclase and clinopyroxene polyhedral Young's moduli provided strong support in favour of using lattice-strain models to interpret partitioning data (Blundy and Wood 1994). However, although Eq. 4 holds well in these cases, it significantly underestimates the high fitted $E$ values for $3+$ elements entering the large site in garnets and majorites (van Westrenen et al. 2000a, b).

Young's moduli of garnet structures cover the range 245-275 GPa (depending on chemical composition), virtually identical to the range for reported majorite values (240-285 GPa) (Whitney et al. 2007; van Westrenen unpublished compilation). Corrected from the nominal charge of $2+$ to a charge of $3+$ using the Hazen and Finger (1979) formalism, this translates into 'expected' $E$ values between 360 and $428 \mathrm{GPa}$. All apparent Young's moduli derived from garnet-melt and majorite-melt partitioning datasets lie significantly above this range. The discrepancy becomes even larger when considering that the Young's modulus of the garnet $\mathrm{XO}_{8}$ polyhedron is lower than that of the garnet structure as a whole, as it is the most compressible polyhedron in the structure. For example, the measured Young's modulus of the $\mathrm{MgO}_{8}$ in pyrope is 160 $\pm 1 \mathrm{GPa}$, compared to $257 \pm 3 \mathrm{GPa}$ for the bulk mineral (Zhang et al. 1998).

As noted previously (van Westrenen et al. 2000a, b), the Hazen and Finger relation (Eq. 4) therefore cannot be used as a predictive model for $E$. Garnets and majorites are not unique in this respect: even larger deviations have been reported for the clinopyroxene M1 site (Hill et al. 2000) and the $\mathrm{Zr}$ site in zircon (e.g., Hanchar and van Westrenen 2007). Van Westrenen et al. (2000b) extensively discussed possible reasons for the mismatch between apparent Young's modulus and 'true' modulus, and we refer the reader to that publication for more information.

van Westrenen et al. (2000a) took an alternative, empirical approach to predicting $E$. They found that, in 
accordance with data compilations by Anderson (1972) for oxide, halide and sulphide compounds, a power law dependence of $E$ on $r_{0}$ could reproduce observed $E$ values:

$$
\begin{gathered}
E(\text { REE in garnet, GPa })=1.17 \times 10^{12} Z_{\mathrm{c}} \\
\left(1.38+r_{0}(\text { REE in garnet, } \AA)\right)^{-26.7} .
\end{gathered}
$$

Figure 6 shows how poorly Eq. 5 performs when applied to Si-rich (majorite-bearing) and Ti-rich experimental data. On average, Eq. 5 overestimates $E$ values for all data obtained at $P>5 \mathrm{GPa}$ by $>300 \mathrm{GPa}$, far exceeding the average error on the fitted value of $E$ in this pressure range (73 GPa). A fundamental shortcoming of Eq. 5 in light of majorite-melt partitioning data is that it predicts rapidly increasing $E$ values as $r_{0}$ decreases (crosses in Fig. 6). All studies of majorite-melt and Ti-rich garnet-melt partitioning of REE listed in Table 1 (Draper et al. 2003, 2006; Corgne and Wood 2004; Walter et al. 2004; Dwarzski et al. 2006) agree that fitted $E$ values for $\mathrm{Si} / \mathrm{Ti}$-rich garnets are smaller than $E$ values for garnets without a majorite/Ti component, while at the same time fitted (and predicted) values of $r_{0}$ in majoritic garnets are smaller (squares in Fig. 6).

This observation is incompatible with any simple mineral-physics based theoretical model for the variation of Young's modulus with crystal lattice site dimension. Its origin may lie in the energetics of charge-balancing the incorporation of trivalent REE into the divalent X-site as mentioned above (e.g., van Westrenen 2000b; Dwarzski

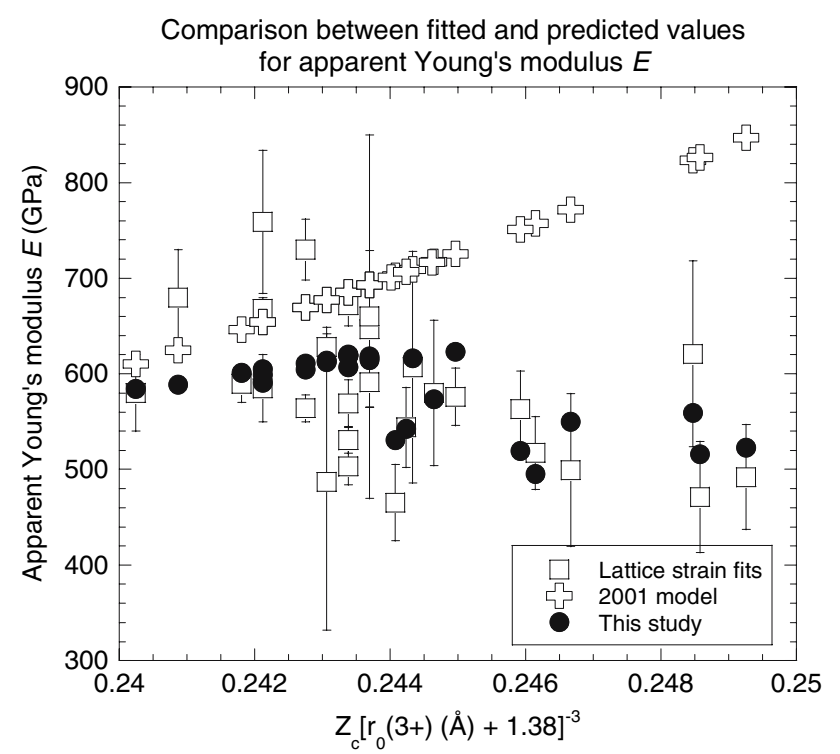

Fig. 6 Comparison between fitted values of apparent Young's modulus E (squares), predicted values from the 2001 model (crosses) and the new predictions using Eq. 4 from this study (circles). Error bars are $1 \sigma$ et al. 2006), or possibly in anomalous behaviour of the compressibility of the majorite $\mathrm{X}$-site compared to the $\mathrm{X}$ site in non-majoritic garnet. In the absence of detailed models for the compressibility of the majoritic garnet $\mathrm{X}$ site, we have opted for the new predictive $E$ model to be empirical in nature. The new model was constructed through linear regression of observed $E$ values against temperature, pressure, and an explicit measure of the extent of the majorite component (Eq. 6, with $r_{0}$ taken from Eq. 2, $P$ in GPa, $T$ in Kelvin, and $(\mathrm{Al}+\mathrm{Cr})_{\text {apfu }}$ the number of atoms per formula unit (12 oxygen) of $\mathrm{Al}$ and $\mathrm{Cr}$ in garnet):

$$
\begin{aligned}
& E(\mathrm{GPa})=2826( \pm 174)\left(1.38+r_{0}\right)^{-3} \\
& \quad+12.4( \pm 1.3) P-0.072( \pm 0.007) T \\
& \quad+237( \pm 8)(\mathrm{Al}+\mathrm{Cr})_{\mathrm{apfu}}
\end{aligned}
$$

The signs of the regressed temperature and pressure terms are physically realistic: minerals become more incompressible as $P$ increases, leading to larger $E$, whereas they become more easily compressible as $T$ increases, leading to smaller $E$. As the concentrations of $4+$ cations on the garnet $\mathrm{Y}$-site $(\mathrm{Si}$ and $\mathrm{Ti})$ increase, $(\mathrm{Al}+\mathrm{Cr})_{\text {apfu }}$ decreases, leading to a decrease in $E$, as observed. Figure 6 shows how good the agreement is between fitted and predicted values of $E$, compared to previous model predictions (van Westrenen et al. 2001; Wood and Blundy 2002). Equation 6 predicts $E$ for all experiments in Table 1 to within $78 \mathrm{GPa}$ $(1 \sigma)$. This value is close to the average standard deviation for fitted values of $E$ ( $52 \mathrm{GPa}, 1 \sigma$ ), and constitutes a major improvement compared to the average standard deviation of $221 \mathrm{GPa}(1 \sigma)$ achievable with the old calibration.

A new model for $D_{0}$ : thermodynamic treatment

\section{Governing equations}

Previous studies have shown that $D_{0}$ values can be linked to the major element composition of both mineral and coexisting melt, pressure and temperature (e.g., Blundy and Wood 2003a). We quantified the dependence of $D_{0}$ on each of these variables using the thermodynamic approach pioneered by Blundy et al. (1995), as subsequently used for the prediction of clinopyroxene-melt and garnet-melt REE D's (Wood and Blundy 1997, 2002; van Westrenen et al. 2001). For an extensive discussion of the philosophy behind this approach we refer the reader to van Westrenen et al. (2001).

The basis of a thermodynamic treatment of garnet-melt $D_{0}$ variations for the rare-earth elements is a fusion equilibrium for a fictive garnet component (defined in general terms as 'J-garnet' in the discussion below) that 
incorporates a hypothetical rare-earth element $\mathrm{J}^{3+}$ with ideal radius $r_{0}$ :

$\mathrm{J}$-garnet $($ garnet $)=\mathrm{J}$-garnet $($ melt $)$.

Taking the standard states to be pure J-garnet solid and liquid at the $P$ and $T$ of interest, the standard state Gibbs free energy change $\Delta G_{\mathrm{f}}^{0}$ for this reaction at $P$ and $T$ is then given by

$$
\begin{aligned}
& \Delta G_{\mathrm{f}(P, T)}^{0}=\Delta H_{\mathrm{f}\left(0.1, T_{\mathrm{f}}\right)}^{0}+\int_{T_{\mathrm{f}}}^{T} \Delta C_{P}^{0} \mathrm{~d} T \\
& -T\left[\Delta S_{\mathrm{f}\left(0.1, T_{\mathrm{f}}\right)}^{0}+\int_{T_{\mathrm{f}}}^{T}\left(\frac{\Delta C_{P}^{0}}{T}\right) \mathrm{d} T\right]+\int_{0.1 \mathrm{MPa}}^{\mathrm{P}} \Delta V^{0} \mathrm{~d} P
\end{aligned}
$$

where $\Delta H_{\mathrm{f}\left(0.1, T_{\mathrm{f}}\right)}^{0}, \Delta C_{P}^{0}, \Delta S_{\mathrm{f}\left(0.1, T_{\mathrm{f}}\right)}^{0}, \quad$ and $\quad \Delta V^{0}$, denote differences in thermodynamic properties between pure Jgarnet melt and crystal at $0.1 \mathrm{MPa}$ and $T_{\mathrm{f}}$ (the hypothetical melting temperature of pure J-garnet at $0.1 \mathrm{MPa})$. Along the melting curve of pure J-garnet $\Delta G_{\mathrm{f}}^{0}(P, T)=0$, leading to

$$
\begin{aligned}
& \Delta H_{\mathrm{f}\left(0.1, T_{\mathrm{f}}\right)}^{0}-T \Delta S_{\mathrm{f}\left(0.1, T_{\mathrm{f}}\right)}^{0} \\
& =-\int_{T_{\mathrm{f}}}^{T} \Delta C_{P}^{0} \mathrm{~d} T+T \int_{T_{\mathrm{f}}}^{T}\left(\frac{\Delta C_{P}^{0}}{T}\right) \mathrm{d} T-\int_{0.1 \mathrm{MPa}}^{\mathrm{P}} \Delta V^{0} \mathrm{~d} P .
\end{aligned}
$$

In natural systems where garnet and melt coexist, the compositions of crystals and melts are not equal to those of pure J-garnet. In this case, instead of being equal to zero, $\Delta G_{\mathrm{f}}^{0}$ in Eq. 8 will depend on the activities $(a)$ of the Jgarnet component in garnet and melt:

$\Delta G_{\mathrm{f}(P, T)}^{0}=R T \ln \left(\frac{a_{\mathrm{J}-\text { garnet }}^{\text {ganet }}}{a_{\mathrm{J}-\text { garnet }}^{\text {melt }}}\right)$.

Equation 9 then becomes

$$
\begin{aligned}
\Delta H_{\mathrm{f}\left(0.1, T_{\mathrm{f}}\right)}^{0}-T \Delta S_{\mathrm{f}\left(0.1, T_{\mathrm{f}}\right)}^{0}= & -\int \Delta C_{P}^{0} \mathrm{~d} T+T \int\left(\frac{\Delta C_{P}^{0}}{T}\right) \mathrm{d} T \\
& -\int \Delta V^{o} \mathrm{~d} P+R T \ln \left(\frac{a_{\mathrm{J}-\text { garnet }}^{\text {garnet }}}{a_{\mathrm{J}-\text { garnet }}^{\text {melt }}}\right)
\end{aligned}
$$

Again, the enthalpy, entropy, volume and heat capacity terms in Eq. 11 refer to properties of solid and molten J-garnet. Equation 11 can be simplified further by noting that (a) the $\Delta C_{P}^{0}$ term can be neglected as it is much smaller than the other terms in Eq. 11 over wide temperature ranges (Wood and Fraser 1976; Wood and Blundy 1997) (b) in the pressure range relevant to garnet-melt partitioning models, volumes of fusion are close to linear functions of pressure. These simplifications lead to

$$
\begin{aligned}
& \Delta H_{\mathrm{f}\left(0.1, T_{\mathrm{f}}\right)}^{0}-T \Delta S_{\mathrm{f}\left(0.1, T_{\mathrm{f}}\right)}^{0}+P \Delta V+\frac{1}{2}\left(\frac{\partial \Delta V}{\partial P}\right) P^{2} \\
& \quad=R T \ln \left(\frac{a_{\mathrm{J}-\text { garnet }}^{\text {garnet }}}{a_{\mathrm{J}-\text { garnet }}^{\text {melt }}}\right) .
\end{aligned}
$$

The chemical composition and activity-composition relations of J-garnet can not be deduced by independent means. They are obtained through a trial-and-error procedure, using Eq. 12 to decide if assumptions are thermodynamically realistic. Because of the many variables involved, thermodynamically acceptable solutions are not necessarily unique. van Westrenen et al. (2001) assumed the J-garnet composition to be $\mathrm{JMg}_{2} \mathrm{Al}_{3} \mathrm{Si}_{2} \mathrm{O}_{12}$, a fictive REE-pyrope garnet incorporating $\mathrm{J}$ via a yttrium-aluminum garnet (YAG, $\mathrm{Y}_{3} \mathrm{Al}_{5} \mathrm{O}_{12}$ )-type charge-balancing mechanism. They also considered the simplest possible activity-composition models for J-garnet in both garnet and melt, and then used the 18 garnet-melt REE partitioning data sets available at the time to deduce the enthalpy, entropy, and volume of fusion of $\mathrm{JMg}_{2} \mathrm{Al}_{3} \mathrm{Si}_{2} \mathrm{O}_{12}$ through Eq. 12.

As mentioned above, this model fails to predict correctly both majorite-melt $D$ 's (Draper et al. 2003, 2006; Dwarzski et al. 2006) and garnet-melt $D$ 's at relatively low temperatures (e.g., Klemme et al. 2002; Bennett et al. 2004; Pertermann et al. 2004). The major extension in pressure, temperature, and bulk compositional range of the data available for this study allowed us to re-evaluate our previous choice of J-garnet component. This analysis strongly suggests that a fictive REE-almandine garnet component, $\mathrm{JFe}_{2} \mathrm{Al}_{3} \mathrm{Si}_{2} \mathrm{O}_{12}$, leads to a more accurate description of the thermodynamics of garnet-melt REE partitioning, both at high pressures, at low temperatures, and in iron-rich compositions relevant to the Moon and Mars (Draper et al. 2003, 2006).

Analogous to van Westrenen et al. (2001), we made simple assumptions about the activities of $\mathrm{JFe}_{2} \mathrm{Al}_{3} \mathrm{Si}_{2} \mathrm{O}_{12}$ in garnet and melt. Assuming complete ordering on the garnet $\mathrm{Y}$ and $\mathrm{Z}$ sites, and incorporating a measure of garnet nonideality,

$a_{\mathrm{JFe}_{2} \mathrm{Al}_{3} \mathrm{Si}_{2} \mathrm{O}_{12}}^{\text {garnt }}=\frac{27}{4} X_{\mathrm{J}}^{\text {garnet }}\left(\gamma_{\mathrm{Fe}}^{\text {garnet }} X_{\mathrm{Fe}}^{\text {garnet }}\right)^{2}$

where $X_{\tilde{J}}^{\text {garnet }}$ is the mole fraction of $\mathrm{J}$ on the garnet $\mathrm{X}$-site, $X_{\mathrm{Fe}}^{\text {garnet }}=\mathrm{Fe}^{2+} /\left(\mathrm{Mg}+\mathrm{Ca}+\mathrm{Fe}^{2+}+\mathrm{Mn}\right)$. The factor $27 / 4$ in Eq. 13 ensures that the activity of this component in a pure $\mathrm{JFe}_{2} \mathrm{Al}_{3} \mathrm{Si}_{2} \mathrm{O}_{12}$ system remains equal to unity. $\gamma_{\mathrm{Fe}}^{\mathrm{garnet}}$ is the activity coefficient for $\mathrm{Fe}$ in garnet, taking into account 
the significant non-ideality along the almandine-grossular join (e.g., Geiger 1999):

$\gamma_{\mathrm{Fe}}^{\text {garnet }}=\exp \left(\frac{19000\left(X_{\mathrm{Ca}}^{\mathrm{garnet}}\right)^{2}}{8.314 T}\right)$

where $X_{\mathrm{Ca}}^{\mathrm{garnet}}=\mathrm{Ca} /\left(\mathrm{Mg}+\mathrm{Ca}+\mathrm{Fe}^{2+}+\mathrm{Mn}\right)$ and $T$ is in Kelvin.

For the melt, ideal mixing of $\mathrm{JFe}_{2} \mathrm{Al}_{3} \mathrm{Si}_{2} \mathrm{O}_{12}$ with other silicate melt components on a 12 oxygen basis was assumed, leading to

$a_{\mathrm{JFe}_{2} \mathrm{Al}_{3} \mathrm{Si}_{2} \mathrm{O}_{12}}^{\text {melt }}=\frac{27}{4} X_{\mathrm{J}}^{\text {melt }}\left(X_{\mathrm{Fe}}^{\text {melt }}\right)^{2}$

where $X_{\mathrm{J}}^{\text {melt }}$ and $X_{\mathrm{Fe}}^{\text {melt }}$ are the numbers of atoms of $\mathrm{J}$ and $\mathrm{Fe}^{2+}$ per 12 oxygens in the melt, respectively. Again, the factor 27/4 ensures that the activity of this component in a pure $\mathrm{JFe}_{2} \mathrm{Al}_{3} \mathrm{Si}_{2} \mathrm{O}_{12}$ system is one. Making these assumptions, Eq. 12 becomes

$$
\begin{aligned}
& \Delta H_{f\left(0.1, T_{\mathrm{f}}\right)}^{0}-T \Delta S_{\mathrm{f}\left(0.1, T_{\mathrm{f}}\right)}^{0}+P \Delta V+\frac{1}{2}\left(\frac{\partial \Delta V}{\partial P}\right) P^{2} \\
& =R T \ln \left(\left(\gamma_{\mathrm{Fe}}^{\text {garnet }} D_{\mathrm{Fe}}\right)^{2} D_{0}(3+)\right) .
\end{aligned}
$$

The molar fractions $X$ used in Eqs. 13-15 have been converted to weight fractions ( $D$ values) in Eq. 16 making use of the fact that the mean molecular weights of garnets and melts (on a 12 oxygen basis) in anhydrous systems are within $2 \%$ relative of each other (van Westrenen et al. 2001). Equation 16 predicts a quantitative link between a thermodynamic description of the fusion of pure $\mathrm{JFe}_{2} \mathrm{Al}_{3}$ $\mathrm{Si}_{2} \mathrm{O}_{12}$ and the distribution of REE between multi-component, natural garnets and melts. It constitutes a predictive model for $D_{0}$, provided the enthalpy, entropy, and volume of fusion of pure $\mathrm{JFe}_{2} \mathrm{Al}_{3} \mathrm{Si}_{2} \mathrm{O}_{12}$ are known or accurately estimated. At present, no thermodynamic data are available for melting of REE-bearing alumino-silicate garnets. Below we show how $\Delta S_{\mathrm{f}\left(0.1 . T_{\mathrm{f}}\right)}^{0}, \Delta H_{\mathrm{f}\left(0.1 . T_{\mathrm{f}}\right)}^{0}$, and $\Delta V$ can in fact be accurately estimated using partitioning data. We then compare resulting estimates to known measurements of the thermodynamics of melting of end-member garnets.

\section{Entropy of fusion}

The entropy of fusion of $\mathrm{JFe}_{2} \mathrm{Al}_{3} \mathrm{Si}_{2} \mathrm{O}_{12}, \Delta S_{\mathrm{f}\left(P, T_{\mathrm{f}}\right)}^{0}$, can be estimated by analysing a set of partitioning experiments performed at constant pressure over a wide range of temperatures. In this case, the pressure terms in Eq. 16 are constant, and the right hand side of the equation can be calculated from measured values of garnet and melt major element composition, and fitted values of $D_{0} . \Delta S_{\mathrm{f}\left(P . T_{\mathrm{f}}\right)}^{0}$ can then be obtained from the slope of a plot of apparent free energy of fusion versus temperature.

As was the case in 2001, the anhydrous garnet-melt partitioning database is dominated by experiments performed at $3 \pm 0.2 \mathrm{GPa}(n=34$, Table 1$)$. Twenty-five of these are iron-bearing, a requirement to be able to use Eq. 16. Calculated apparent free energies of fusion for $\mathrm{JFe}_{2} \mathrm{Al}_{3} \mathrm{Si}_{2} \mathrm{O}_{12}$ in these $3 \mathrm{GPa}$ experiments are plotted against temperature in Fig. 7. The slope of the resulting straight line gives $\Delta S_{\mathrm{f}\left(3 \mathrm{GPa}, T_{\mathrm{f}}\right)}^{0}=218 \pm 7 \mathrm{Jmol}^{-1} \mathrm{~K}^{-1}$. This value is similar to the best-fit value $226 \pm 23 \mathrm{~J} \mathrm{~mol}^{-1} \mathrm{~K}^{-1}$ previously derived for $\mathrm{JMg}_{2} \mathrm{Al}_{3} \mathrm{Si}_{2} \mathrm{O}_{12}$ (van Westrenen et al. 2001). The $1 \sigma$ error of $7 \mathrm{~J} \mathrm{~mol}^{-1} \mathrm{~K}^{-1}$ derived from analysis of garnet-melt partitioning data approaches typical errors quoted for calorimetric entropy of fusion measurements for garnets (e.g., Newton et al. 1977; Téqui et al. 1991). The error is also significantly smaller than $1 \sigma=$ $23 \mathrm{~J} \mathrm{~mol}^{-1} \mathrm{~K}^{-1}$ previously derived for $\mathrm{JMg}_{2} \mathrm{Al}_{3} \mathrm{Si}_{2} \mathrm{O}_{12}$, due to the much larger temperature range available $(300 \mathrm{~K}$ compared to $150 \mathrm{~K})$. The entropy of fusion is within error of an interpolation between calorimetric data for pure pyrope $\left(\Delta S_{\mathrm{f}\left(0.1 . T_{\mathrm{f}}\right)}^{0}=162 \pm 5 \mathrm{~J} \mathrm{~mol}^{-1} \mathrm{~K}^{-1}\right.$-Newton et al. 1977; $\Delta S_{\mathrm{f}\left(0.1 . T_{\mathrm{f}}\right)}^{0}=154 \mathrm{~J} \mathrm{~mol}^{-1} \mathrm{~K}^{-1}$-Téqui et al. 1991) and YAG (230 J mol ${ }^{-1} \mathrm{~K}^{-1}$ - Lin et al. 1999). Replacement of either $\mathrm{Mg}$ or Fe by trivalent cations, charge-balanced by replacing $\mathrm{Si}$ by $\mathrm{Al}$, thus leads to an increase in the entropy of fusion of the resulting garnet component.

The effect of pressure on $\Delta S_{\mathrm{f}\left(P, T_{\mathrm{f}}\right)}^{0}$, calculated from average garnet thermal expansion data (Fei 1995) to be approximately $8 \mathrm{~J} \mathrm{~mol}^{-1} \mathrm{~K}^{-1}$ over the pressure range from

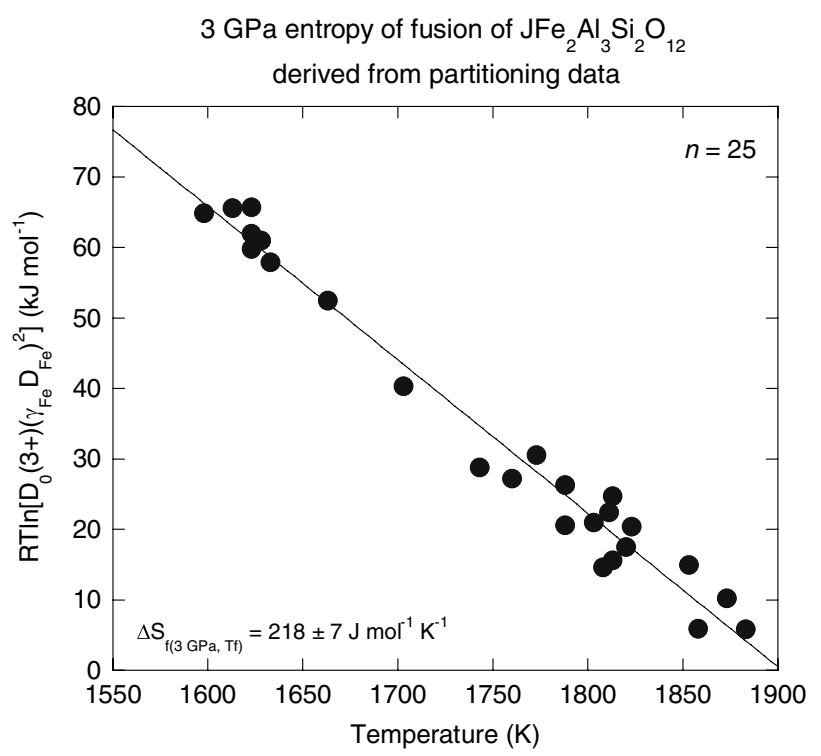

Fig. 7 The apparent free energy of fusion of $\mathrm{JFe}_{2} \mathrm{Al}_{3} \mathrm{Si}_{2} \mathrm{O}_{12}$ plotted against temperature, using $25 \mathrm{Fe}$-bearing experiments at $3 \pm 0.2 \mathrm{GPa}$ from Table 1 . The entropy of fusion of $\mathrm{JFe}_{2} \mathrm{Al}_{3} \mathrm{Si}_{2} \mathrm{O}_{12}$ is derived from the slope of the straight line fitted through the data 


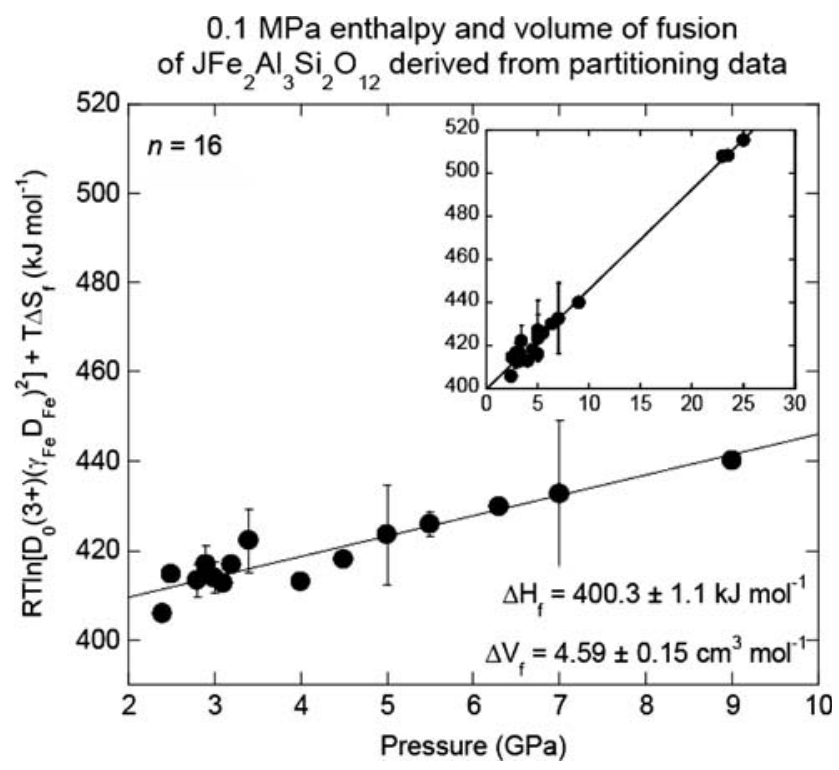

Fig. 8 The apparent free energy of fusion of $\mathrm{JFe}_{2} \mathrm{Al}_{3} \mathrm{Si}_{2} \mathrm{O}_{12}$, corrected for temperature using the entropy of fusion derived in Fig. 7, plotted against pressure (symbols, derived from garnet-melt REE partitioning data for experiments listed in Table 1). The enthalpy and volume of fusion of $\mathrm{JFe}_{2} \mathrm{Al}_{3} \mathrm{Si}_{2} \mathrm{O}_{12}$ are obtained from the intercept and slope, respectively, of a least-squares linear fit to the data between 2.4 and $9 \mathrm{GPa}$. The inset shows how the extrapolation of this 'low-pressure' fit (line) agrees very well with the 23-25 GPa data points

2.5 to $25 \mathrm{GPa}$, is similar to the $1 \sigma$ error resulting from our fitting method $\left(7 \mathrm{~J} \mathrm{~mol}^{-1} \mathrm{~K}^{-1}\right)$. Following van Westrenen et al. (2001) we therefore applied our value of $\Delta S_{\mathrm{f}\left(3 \mathrm{GPa}, T_{\mathrm{f}}\right)}^{0}$ to compensate for the temperature effect on all garnet-melt partitioning data irrespective of pressure. This allows us to estimate the enthalpy and volume of fusion for $\mathrm{JFe}_{2} \mathrm{Al}_{3-}$ $\mathrm{Si}_{2} \mathrm{O}_{12}$ using the partitioning data from Table 1. After rearranging Eq. 16, including our estimate for $\Delta S_{\mathrm{f}\left(P, T_{\mathrm{f}}\right)}^{0}$, we obtain:

$$
\begin{gathered}
R T \ln \left(\left(\gamma_{\mathrm{Fe}}^{\text {garnet }} D_{\mathrm{Fe}}\right)^{2} D_{0}(3+)\right)+218( \pm 7) T \\
=\Delta H_{\mathrm{f}\left(0.1, T_{\mathrm{f}}\right)}^{0}+P \Delta V+\frac{1}{2}\left(\frac{\partial \Delta V}{\partial P}\right) P^{2} .
\end{gathered}
$$

\section{Enthalpy and volume of fusion}

By plotting the left hand side of Eq. 16 against pressure, information is obtained about $\Delta H_{\mathrm{f}\left(0.1, T_{\mathrm{f}}\right)}^{0}$ and $\Delta V_{\mathrm{f}\left(0.1, T_{\mathrm{f}}\right)}^{0}$ (Fig. 8). Experiments are now available at 19 different pressures between 2.4 and $25 \mathrm{GPa}$ (Table 1), compared to four pressures in the van Westrenen et al. (2001) model. The pressure dependence in Fig. 8 appears to be linear rather than parabolic. In contrast to the model of Wood and Blundy (2002) we argue that the pressure derivative of the volume change $\left(\frac{\partial \Delta V}{\partial P}\right)$ in Eq. 17 is therefore negligible. We note that this conclusion could change once reliable majorite-melt partitioning data filling in the pressure gap between 9 and $23 \mathrm{GPa}$ become available.

The pressure range for which garnet-melt partitioning data are now available is very large. As a result, inferences about pressure and temperature dependencies on garnetmelt $D$ values, especially at the highest pressures, could be affected by inter-laboratory differences in pressure calibration. To prevent unwarranted propagation of possible pressure calibration errors, the slope and intercept of the best-fit line in Fig. 8 were derived from data obtained between 2.4 and $9 \mathrm{GPa}$ only, leading to $\Delta H_{\mathrm{f}\left(0.1, T_{\mathrm{f}}\right)}^{0}=400.3 \pm$ $1.1 \mathrm{~kJ} \mathrm{~mol}^{-1}$ and $\Delta V_{\mathrm{f}\left(0.1, T_{\mathrm{f}}\right)}^{0}=4.59 \pm 0.15 \mathrm{~cm}^{3} \mathrm{~mol}^{-1}$. As seen in the inset of Fig. 8, these values are fully consistent with the 23-25 GPa data. We conclude that there are no systematic errors in pressure calibration between the lower and higher pressure data sets in Table 1.

The enthalpy of fusion of $\mathrm{JFe}_{2} \mathrm{Al}_{3} \mathrm{Si}_{2} \mathrm{O}_{12}$ is similar to the value of $418 \pm 12 \mathrm{~kJ} \mathrm{~mol}^{-1}$ previously obtained for $\mathrm{JMg}_{2} \mathrm{Al}_{3} \mathrm{Si}_{2} \mathrm{O}_{12}$ by van Westrenen et al. (2001). However, the volume of fusion of $\mathrm{JFe}_{2} \mathrm{Al}_{3} \mathrm{Si}_{2} \mathrm{O}_{12}$ is less than half the value of $\Delta V_{\mathrm{f}\left(0.1, T_{\mathrm{f}}\right)}^{0}=10.4 \pm 1.0 \mathrm{~cm}^{3} \mathrm{~mol}^{-1}$ derived for $\mathrm{JMg}_{2} \mathrm{Al}_{3} \mathrm{Si}_{2} \mathrm{O}_{12}$. Again, errors in the thermodynamic fusion properties of $\mathrm{JFe}_{2} \mathrm{Al}_{3} \mathrm{Si}_{2} \mathrm{O}_{12}$ are significantly reduced because of the growth of the data set covering a much wider pressure range. Calorimetric data on YAG (Lin et al. 1999) show that YAG has an estimated $\Delta H_{\mathrm{f}\left(0.1, T_{\mathrm{f}}\right)}^{0}$ of $516 \mathrm{~kJ} \mathrm{~mol}^{-1}$. Our derived value of $400.3 \pm 1.1 \mathrm{~kJ} \mathrm{~mol}^{-1}$ is therefore what might be expected from a progression from pyrope to YAG. The estimated melting point of $\mathrm{JFe}_{2} \mathrm{Al}_{3} \mathrm{Si}_{2} \mathrm{O}_{12}$ is $1,835 \pm 60 \mathrm{~K}$, slightly lower than that of $\mathrm{JMg}_{2} \mathrm{Al}_{3} \mathrm{Si}_{2} \mathrm{O}_{12}$ $\left(T_{\mathrm{f}}=1,850 \pm 140 \mathrm{~K}\right.$, van Westrenen et al. 2001), in accordance with an observed decrease in melting temperature going from pyrope to almandine (Butvina et al. 2001). $T_{\mathrm{f}}$ is in between the known values for pyrope $(1,570 \pm$ $30 \mathrm{~K}$, van Westrenen et al. 2001) and YAG $(1,970 \pm 30 \mathrm{~K}$, Fratello and Brandle 1993).

\section{Predicting $D_{0}$}

In summary, the entropy of fusion of hypothetical REE garnet compound $\mathrm{JFe}_{2} \mathrm{Al}_{3} \mathrm{Si}_{2} \mathrm{O}_{12}$, derived from garnet-melt REE partitioning data, is $218 \pm 7 \mathrm{~J} \mathrm{~mol}^{-1} \mathrm{~K}^{-1}$, its enthalpy of fusion is $400.3 \pm 1.1 \mathrm{~kJ} \mathrm{~mol}^{-1}$, and its volume of fusion is $4.59 \pm 0.15 \mathrm{~cm}^{3} \mathrm{~mol}^{-1}$. These values can be used to predict $D_{0}$, using Eq. 17 (where $R$ is the gas constant, $T$ in Kelvin, $P$ in GPa, and $\gamma_{\mathrm{Fe}}^{\text {garnet }}$ is taken from Eq. 14), to yield

$$
\begin{aligned}
& D_{0} \text { (REE) } \\
& \quad=\exp \left(\frac{400290( \pm 1100)+4586( \pm 150) P-218( \pm 7) T}{R T}\right) /\left(\gamma_{\mathrm{Fe}}^{\text {garnet }} D_{\mathrm{Fe}}\right)^{2} .
\end{aligned}
$$




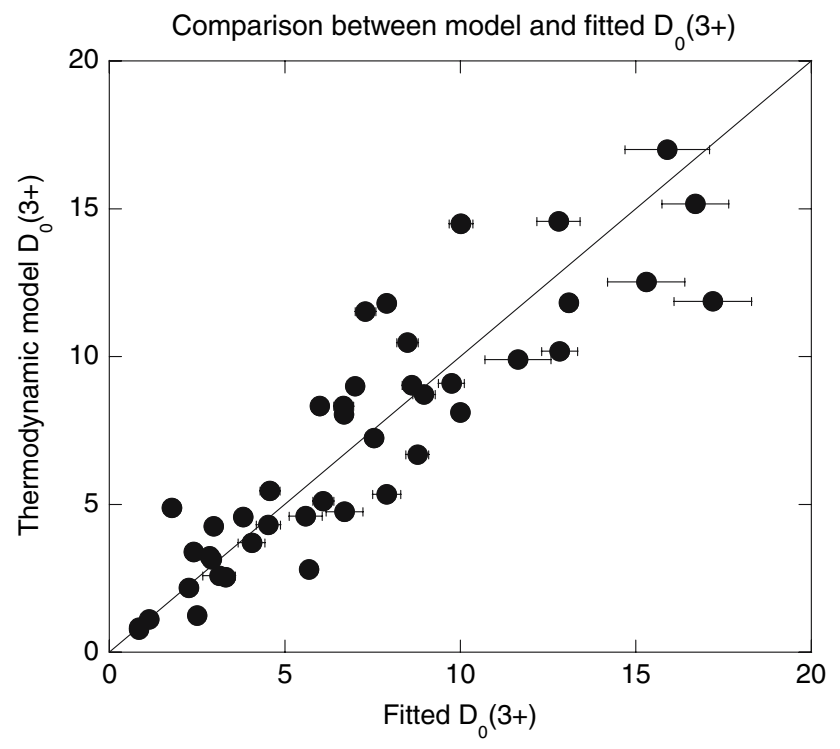

Fig. 9 Comparison between fitted $D_{0}$ and thermodynamically predicted $D_{0}$ (Eq. 18) for experiments listed in Table 1
Equation 18 does not incorporate any explicit term to deal with effects on $D_{0}$ of increasing $\mathrm{Si}$ (as pressure increases) or increasing $\mathrm{Ti}$ concentrations in the garnet $\mathrm{Y}$-site. Si and $\mathrm{Ti}$ on the garnet $\mathrm{Y}$-site to a first degree do not appear to influence the thermodynamics of REE exchange between garnet and melt. Eq. 18 does not take into account the possible influence of melt structure and/or composition on garnet-melt partitioning, apart from incorporating an explicit dependence on the Fe content of the melt through the $D_{\mathrm{Fe}}$ term. Whether melt composition and/or structure are important variables in mineral-melt partitioning continues to be hotly debated (e.g., Blundy and Wood 2003a; Gaetani 2004; Schmidt et al. 2006). In the companion paper (Draper and van Westrenen this issue) we will show that an alternative, statistical parameterisation of $D_{0}$ variations requires incorporation of an an additional term involving $\mathrm{Fe}-\mathrm{Mg}$ exchange between garnet and coexisting melt. Both $D_{0}$ models reproduce experimental data equally well. We conclude that the currently available garnet-melt partitioning data base cannot be used to argue either for or
Fig. 10 Comparison between measurements (symbols) and predictions using the models for $r_{0}, E$, and $D_{0}$ presented in this study (solid curves, constructed by combining Eqs. 1, 3, 6, and 18). Data are shown for a representative low-pressure, low-temperature garnet (a, from Salters et al. 2002), and representative majorite-poor and majorite-rich garnets at high $P$ and $T$ (b, from Dwarzski et al. 2006 and $\mathbf{c}$, from Tuff and Gibson 2007). Dotted curves in c illustrate how predicted values vary if experimental charges were at temperatures $25 \mathrm{~K}$ lower (upper curve) or higher (lower curve) than indicated by the thermocouple junction
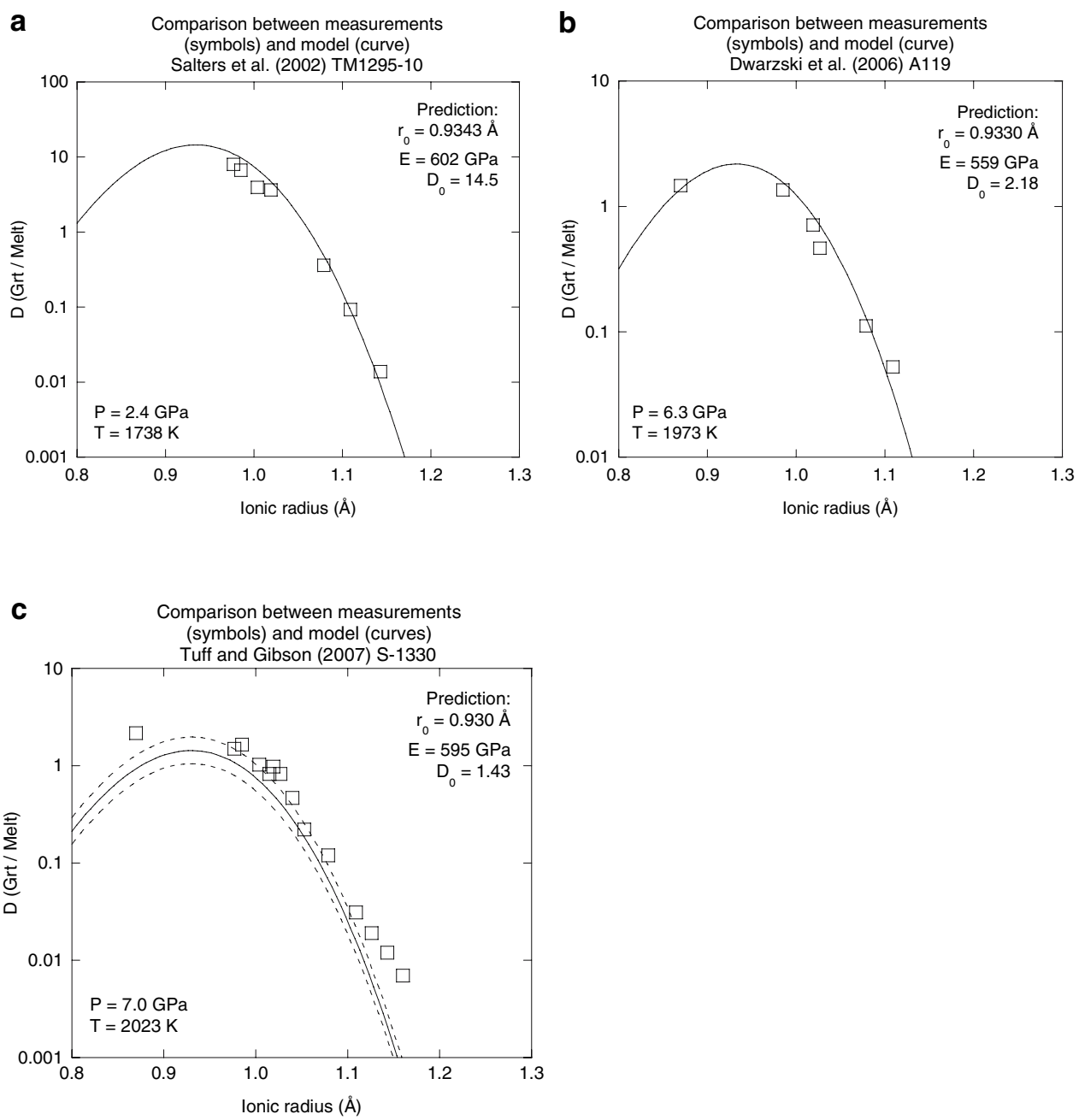
Table 2 Mismatches (in per cent) between measured and predicted values of garnet-melt partition coefficients from Table 1

\begin{tabular}{lccccccccccc}
\hline Mismatch (per cent) & $\mathrm{Ce}$ & $\mathrm{Nd}$ & $\mathrm{Sm}$ & $\mathrm{Eu}$ & $\mathrm{Gd}$ & $\mathrm{Dy}$ & $\mathrm{Er}$ & $\mathrm{Yb}$ & $\mathrm{Lu}$ & $\mathrm{Y}$ & $\mathrm{Sc}$ \\
\hline Minimum & 25 & 10 & 0.2 & 3.0 & 2.1 & 5.0 & 1.7 & 0.0 & 2.2 & 1.0 & 0.8 \\
Maximum & 96 & 127 & 103 & 117 & 61 & 218 & 73 & 160 & 74 & 147 & 131 \\
Average & 70 & 53 & 42 & 37 & 26 & 50 & 25 & 37.1 & 33 & 38 & 33 \\
\hline
\end{tabular}

against a melt compositional effect on garnet-melt $D$ values.

A comparison between predicted and fitted $D_{0}$ values for the REE, Y and Sc for the experiments from Table 1 is shown in Fig. 9. $D_{0}$ values varying by over one order or magnitude can be predicted with confidence across the $P-T$ range of garnet stability, including pressures of $25 \mathrm{GPa}$.

Together, Eqs. 1, 3, 6 and 18 can be used to predict $D_{\text {REE,Y,Sc }}$ as a function of pressure, temperature, garnet major element composition, and $D_{\mathrm{Fe}}$. Three examples of this are shown in Fig. 10. Figure 10c shows a comparison between our predictive model and a recently published dataset (Tuff and Gibson 2007) which was not used for any aspect of model construction. To highlight the sensitivity of our model to temperature variations, dotted curves in Fig. 10c illustrate how model predictions vary if temperature is raised or lowered by $25 \mathrm{~K}$ compared to the experimental run temperature quoted in Tuff and Gibson (2007). Errors in experimental temperatures on the order of $\pm 25 \mathrm{~K}$ are common at the high temperatures required to equilibrate garnet and melt at pressures $>3 \mathrm{GPa}$, and this could well be a reason for some of the relatively small remaining discrepancies between model and data.

Table 2 lists standard deviations of the difference between predicted and observed $D_{\mathrm{REE}, \mathrm{Y}, \mathrm{Sc}}($ total $n>300)$ that stem from the propagation of errors in the prediction of the three individual lattice-strain parameters. These deviations average from $25 \%$ for $\mathrm{Er}$ to $70 \%$ for Ce. The maximum error in $D$ prediction is $218 \%$ for one measurement of $D_{\text {Dy }}$. This is remarkably low considering the total spread in

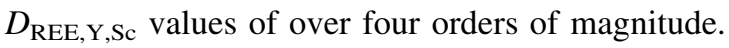

\section{Conclusion}

Accurate prediction of garnet-anhydrous melt and majorite-anhydrous melt $D$ 's for the REE, Y and Sc is possible with a single thermodynamic, lattice-strain based model. Our calibration is capable of predicting $D$ 's to use in modelling of partial melting processes at pressures covering the entire stability range of magmatic garnets in the Earth, Moon and Mars.

Acknowledgments This work was funded by US NSF grant EAR0337237 to DSD and a European Young Investigator (EURYI) award to WvW. Comments by Marc Hirschmann, Yakov Khazan, and an anonymous reviewer greatly improved the clarity of this manuscript. We thank Lee Ann Lloyd, Janice Noruk, Rama Murthy, and the Community of Corrales, NM for fantastic logistical support. Surprising input by S. I. van Westrenen is gratefully acknowledged.

\section{References}

Allègre CJ, Minster JF (1978) Quantitative models of trace element behavior in magmatic processes. Earth Planet Sci Lett 38:1-25

Anderson OL (1972) Patterns in elastic constants of minerals important to geophysics. In: Robertson EC (ed) The nature of the solid earth. McGraw-Hill, New York, pp 575-613

Beattie P (1994) Systematics and energetics of trace-element partitioning between olivine and silicate melts: implications for the nature of mineral/melt partitioning. Chem Geol 117:57-71

Beattie P, Drake M, Jones J, Leeman W, Longhi J, McKay G, Nielsen R, Palme H, Shaw D, Takahashi E, Watson B (1993) Terminology for trace-element partitioning. Geochim Cosmochim Acta 57:1605-1606

Bennett SL, Blundy J, Elliott T (2004) The effect of sodium and titanium on crystal-melt partitioning of trace elements. Geochim Cosmochim Acta 68:2335-2347

Blundy JD, Wood BJ (1994) Prediction of crystal-melt partition coefficients from elastic moduli. Nature 372:452-454

Blundy JD, Wood BJ (2003a) Partitioning of trace elements between crystals and melts. Earth Planet Sci Lett 210:383-397

Blundy JD, Wood BJ (2003b) Mineral-melt partitioning of uranium, thorium and their daughters. Rev Miner Geochem 52:39-123

Blundy JD, Falloon TJ, Wood BJ, Dalton JA (1995) Sodium partitioning between clinopyroxene and silicate melts. J Geophys Res 100:15501-15515

Borg LE, Draper DS (2003) A petrogenetic model for the origin and compositional variation of the martian basaltic meteorites. Meteor Planet Sci 38:1713-1731

Brice JC (1975) Some thermodynamic aspects of the growth of strained crystals. J Crystal Growth 28:249-253

Butvina VG, Bobrov AV, Litvin YA (2001) Experimental study of the pyrope-grossular-almandine system at $6.5 \mathrm{GPa}$ and 1500 $1900^{\circ} \mathrm{C}$. Doklady Academii nauk 379:655-658 (in Russian)

Corgne A, Wood BJ (2004) Trace element partitioning between majoritic garnet and silicate melt at $25 \mathrm{GPa}$. Phys Earth Planet Int 143-144:407-419

Drake MJ, McFarlane EA, Gasparik T, Rubie DC (1993) Mgperovskite/silicate melt and majorite garnet/silicate melt partition coefficients in the system $\mathrm{CaO}-\mathrm{MgO}-\mathrm{SiO}_{2}$ at high temperatures and pressures. J Geophys Res 98:5427-5431

Draper DS, Xirouchakis D, Agee CB (2003) Trace element partitioning between garnet and chondritic melt from 5 to $9 \mathrm{GPa}$ : implications for the onset of the majorite transition in the martian mantle. Phys Earth Planet Int 139:149-169

Draper DS, duFrane SA, Shearer CK, Dwarzski RE, Agee CB (2006) High-pressure phase equilibria and element partitioning experiments on Apollo 15 green C picritic glass: implications for the role of garnet in the deep lunar interior. Geochim Cosmochim Acta 70:2400-2416 
Dwarzski RE, Draper DS, Shearer CK, Agee CB (2006) Preliminary insights on the crystal chemistry of high titanium garnets from partitioning of rare earth and high field strength elements. Am Mineral 91:1536-1546

Fei Y (1995) Thermal expansion. In: Mineral physics and crystallography. A handbook of physical constants. AGU reference shelf 2, pp 29-44

Fratello VJ, Brandle CD (1993) Physical properties of a $\mathrm{Y}_{3} \mathrm{Al}_{5} \mathrm{O}_{12}$ melt. J Crystal Growth 128:1006-1010

Gaetani GA (2004) The influence of melt structure on trace element partitioning near the peridotite solidus. Contrib Mineral Petrol 147:511-527

Gast PW (1968) Trace element fractionation and the origin of tholeiitic and alkaline magma types. Geochim Cosmochim Acta 32:1057-1086

Geiger CA (1999) Thermodynamics of $\left(\mathrm{Fe}^{2+}, \mathrm{Mn}^{2+}, \mathrm{Mg}, \mathrm{Ca}\right)_{3} \mathrm{Al}_{2-}$ $\mathrm{Si}_{3} \mathrm{O}_{12}$ garnet: a review and analysis. Mineral Petrol 66:271-299

Gibbs GV, Smith JV (1965) Refinement of the crystal structure of synthetic pyrope. Am Mineral 50:2032-2039

Goldschmidt VM (1937) The principles of distribution of chemical elements in minerals and rocks. J Chem Soc 655:655-673

Hanchar JM, van Westrenen W (2007) Rare earth element behavior in zircon/melt systems. Elements 3:37-42

Hauri EH, Wagner TP, Grove TL (1994) Experimental and natural partitioning of $\mathrm{Th}, \mathrm{U}, \mathrm{Pb}$ and other trace elements between garnet, clinopyroxene and basaltic melts. Chem Geol 117:149_ 166

Hazen RM, Finger LW (1979) Bulk modulus-volume relationship for cation-anion polyhedra. J Geophys Res 84:6723-6728

Hellebrand E, Snow JE, Hoppe P, Hofmann AW (2002) Garnet-field melting and late-stage refertilization in 'residual' abyssal peridotites from the Central Indian ridge. J Petrol 43:2305-2338

Hertogen J, Gijbels R (1976) Calculation of trace element fractionation during partial melting. Geochim Cosmochim Acta 40:313322

Hill E, Wood BJ, Blundy JD (2000) The effect of Ca-Tschermaks component on trace element partitioning between clinopyroxene and silicate melt. Lithos 53:203-215

Johnson KTM (1998) Experimental determination of partition coefficients for rare earth and high-field-strength elements between clinopyroxene, garnet, and basaltic melt at high pressures. Contrib Mineral Petrol 133:60-68

Kato T, Ringwood AE, Irifune T (1988) Experimental determination of element partitioning between silicate perovskites, garnets and liquids: constraints on early differentiation of the mantle. Earth Planet Sci Lett 89:123-145

Klemme S, Blundy JD, Wood BJ (2002) Experimental constraints on major and trace element partitioning during partial melting of eclogite. Geochim Cosmochim Acta 66:3109-3123

Lin I-C, Navrotsky A, Weber JKR, Nordine PC (1999) Thermodynamics of glass formation and metastable solidification of molten $\mathrm{Y}_{3} \mathrm{Al}_{5} \mathrm{O}_{12}$. J Non-Cryst Sol 243:273-276

Merli M, Callegari A, Cannillo E, Caucia F, Leona M, Oberti R, Ungaretti L (1995) Crystal-chemical complexity in natural garnets: structural constraints on chemical variability. Eur J Mineral 7:1239-1249

Moriyama J, Kawabe I, Fujino K, Ohtani E (1992) Experimental study of element partitioning between majorite, olivine, merwinite, diopside and silicate melts at $16 \mathrm{GPa}$ and $2000^{\circ} \mathrm{C}$. Geochem J 26:357-382

Mysen BO (2004) Element partitioning between minerals and melt, melt composition, and melt structure. Chem Geol 213:1-24

Nagasawa H (1966) Trace element partition coefficient in ionic crystals. Science 152:767-769

Neal CR (2001) Interior of the Moon: the presence of garnet in the primitive deep lunar mantle. J Geophys Res 106:27865-27885
Neumann H, Mead J, Vitaliano CJ (1954) Trace element variation during fractional crystallization as calculated from the distribution law. Geochim Cosmochim Acta 6:90-99

Newton RC, Charlu TV, Kleppa OJ (1977) Thermochemistry of high pressure garnets and clinopyroxenes in the system $\mathrm{CaO}-\mathrm{MgO}$ $\mathrm{Al}_{2} \mathrm{O}_{3}-\mathrm{SiO}_{2}$. Geochim Cosmochim Acta 41:369-377

Ohtani E, Kawabe I, Moriyama J, Nagata Y (1989) Partitioning of elements between majorite garnet and melt and implications for petrogenesis of komatiite. Contrib Mineral Petrol 103:263-269

Onuma N, Higuchi H, Wakita H, Nagasawa H (1968) Trace element partition between two pyroxenes and the host lava. Earth Planet Sci Lett 5:47-51

Pertermann M, Hirschmann MM, Hametner K, Günther D, Schmidt MW (2004) Experimental determination of trace element partitioning between garnet and silica-rich liquid during anhydrous partial melting of MORB-like eclogite. Geochem Geophys Geosys 5. doi: 10.1029/2003GC00063810.1029/2003GC000638

Press WH, Teukolsky SA, Vetterling WT, Flannery BP (1992) Numerical recipes in C. Cambridge University Press, Cambridge, p 965

Prowatke S, Klemme S (2005) Effect of melt composition on the partitioning of trace elements between titanite and silicate melt. Geochim Cosmochim Acta 69:695-709

Quartieri S, Antonioli G, Geiger CA, Artioli G, Lottici PP (1999a) XAFS characterization of the structural site of $\mathrm{Yb}$ in synthetic pyrope and grossular garnets. Phys Chem Minerals 26:251-256

Quartieri S, Chaboy J, Antonioli G, Geiger CA (1999b) XAFS characterization of the structural site of $\mathrm{Yb}$ in synthetic pyrope and grossular garnets. II: XANES full multiple scattering calculations at the Yb LI- and LIII edges. Phys Chem Minerals 27:88-94

Quartieri S, Boscherini F, Chaboy J, Dalconi MC, Oberti R, Zanetti A (2002) Characterization of trace $\mathrm{Nd}$ and $\mathrm{Ce}$ site preference and coordination in natural melaniets: a combined X-ray diffraction and high-energy XAFS study. Phys Chem Minerals 29:495-502

Quartieri S, Dalconi MC, Boscherini F, Oberti R, D'Acapito F (2004) Changes in the local coordination of trace rare-earth elements in garnets by high-energy XAFS: new data on dysprosium. Phys Chem Minerals 31:162-167

Salters VJM, Hart SR (1989) The hafnium paradox and the role of garnet in the source of mid-ocean-ridge basalts. Nature 342:420 422

Salters VJM, Longhi J (1999) Trace element partitioning during the initial stages of melting beneath mid-ocean ridges. Earth Planet Sci Lett 166:15-30

Salters VJM, Longhi JE, Bizimis M (2002) Near mantle solidus trace element partitioning at pressures up to $3.4 \mathrm{GPa}$. Geochem Geophys Geosys 3. doi: 10.1029/2001GC00014810.1029/ 2001GC000148

Schmidt MW, Connolly JAD, Günther D, Bogaerts M (2006) Element partitioning: the role of melt structure and composition. Science 312:1646-1650

Shaw DM (1953) The camouflage principle and trace-element distribution in magmatic minerals. J Geol 61:142-151

Shaw DM (1970) Trace element fractionation during anatexis. Geochim Cosmochim Acta 34:237-243

Shen Y, Forsyth DW (1995) Geochemical constraints on the initial and final depth of melting beneath mid-ocean ridges. J Geophys Res 100:2211-2237

Téqui C, Robie RA, Hemingway BS, Neuville DR, Richet P (1991) Melting and thermodynamic properties of pyrope $\left(\mathrm{Mg}_{3} \mathrm{Al}_{2-}\right.$ $\mathrm{Si}_{3} \mathrm{O}_{12}$ ). Geochim Cosmochim Acta 55:1005-1010

Tuff J, Gibson SA (2007) Trace-element partitioning between garnet, clinopyroxene and Fe-rich picritic melts at 3 to $7 \mathrm{GPa}$. Contrib Mineral Petrol 153:369-387 
Ungaretti L, Leona M, Merli M, Oberti R (1995) Non-ideal solidsolution in garnet: crystal-structure evidence and modelling. Eur J Mineral 7:1299-1312

Walter MJ, Nakamura E, Trønnes RG, Frost DJ (2004) Experimental constraints on crystallization differentiation in a deep magma ocean. Geochim Cosmochim Acta 68:4267-4284

van Westrenen W, Blundy JD, Wood BJ (1999) Crystal-chemical controls on trace element partitioning between garnet and anhydrous silicate melt. Am Mineral 84:838-847

van Westrenen W, Blundy JD, Wood BJ (2000a) Effect of $\mathrm{Fe}^{2+}$ on garnet-melt trace element partitioning: experiments in FCMAS and quantification of crystal-chemical controls in natural systems. Lithos 53:191-203

van Westrenen W, Allan NL, Blundy JD, Purton JA, Wood BJ (2000b) Atomistic simulation of trace element incorporation into garnets-comparison with experimental garnet-melt partitioning data. Geochim Cosmochim Acta 64:1629-1639

van Westrenen W, Wood BJ, Blundy JD (2001) A predictive thermodynamic model of garnet-melt trace element partitioning. Contrib Mineral Petrol 142:219-234

Whitney DL, Broz M, Cook RF (2007) Hardness, toughness, and modulus of some common metamorphic minerals. Am Mineral 92:281-288
Withers AC (1997) Water in the mantle. Ph.D. thesis, University of Bristol, UK, p 195

Wood BJ, Blundy JD (1997) A predictive model for rare earth element partitioning between clinopyroxene and anhydrous silicate melt. Contrib Mineral Petrol 129:166-181

Wood BJ, Blundy JD (2001) The effect of cation charge on crystalmelt partitioning. Earth Planet Sci Lett 188:59-71

Wood BJ, Blundy JD (2002) The effect of $\mathrm{H}_{2} \mathrm{O}$ on crystal-melt partitioning of trace elements. Geochim Cosmochim Acta 66:3647-3656

Wood BJ, Fraser DG (1976) Elementary thermodynamics for geologists. Oxford University Press, Oxford, 303 p

Yurimoto H, Ohtani E (1992) Element partitioning between majorite and liquid: a secondary ion mass spectrometric study. Geophys Res Lett 19:17-20

Zhang L, Ahsbahs H, Kutoglu A (1998) Hydrostatic compression and crystal structure of pyrope up to $33 \mathrm{GPa}$. Phys Chem Minerals 25:301-307

Zou H, Reid MR (2001) Quantitative modeling of trace element fractionation during incongruent dynamic melting. Geochim Cosmochim Acta 65:153-162 